Pesq. Vet. Bras. 37(4):346-354, abril 2017

DOI: $10.1590 / \mathrm{S} 0100-736 \mathrm{X} 2017000400008$

\title{
Suplementação com imunoestimulante em cadelas com neoplasia mamária maligna: aspectos hematológicos e bioquímicos ${ }^{1}$
}

\author{
Vilma F. Oliveira ${ }^{2}$, Joyce R. Lobo ${ }^{3 *}$, Helton F. Oliveira², Ana Caroline S. Bertão \\ Daniel N.A. Moura ${ }^{5}$, Maria Clorinda S. Fioravanti ${ }^{6}$ e Naida Cristina Borges ${ }^{6}$
}

\begin{abstract}
Oliveira V.F., Lobo J.R., Oliveira H.F., Bertão A.C.S., Moura D.N.A., Fioravanti M.C.S. \& Borges N.C. 2017. [Immunostimulant supplementation for bitches with malignant mammary tumor: hematological and biochemical aspects.] Suplementação com imunoestimulante em cadelas com neoplasia mamária maligna: aspectos hematológicos e bioquímicos. Pesquisa Veterinária Brasileira 37(4):346-354. Departamento de Medicina Veterinária, Escola de Veterinária e Zootecnia, Universidade Federal de Goiás, Campus Samambaia, Avenida Esperança s/n, Campus Universitário, Goiânia, GO 74690-900, Brazil. E-mail: joycerl@hotmail.com

Functional foods have been used as adjuvant for breast cancer treatment of bitches. The aim of the present study was to evaluate hematological and clinical biochemistry response in female dogs diagnosed with malignant mammary tumors and supplemented with functional food. After the mastectomy, 16 bitches were divided into two groups: supplemented (S) and none supplemented (NS) with a commercial product of Saccharomyces cerevisiae, mannanoligosaccharides and nutraceuticals. Chemotherapy with doxorubicin and carboplatin was performed alternately at intervals of 21 days for eight sessions during 168 days of treatment. Clinical and laboratorial assessments was made at the treatment moments. The results of the hemogram (erythrogram, leukogram and platelet count) and serum biochemistry (urea, creatinine, albumin, total and direct bilirubin, alanine aminotransferase, alkaline phosphatase and gamma glutamyltransferase - GGT) were analyzed by Kruskal Wallis test. In the $S$ group, increase body weight was observed, but gastrointestinal disorders or other clinical disorders were not detected over the treatment. In the NS group, loss of weight and clinical disorders were observed. All hematology parameters were normal in the $S$ group; however, leukopenia and lymphopenia were detected in the bitches of the NS group. Among all the clinical biochemistry parameters tested, only serum GGT was increased in the NS group, with no changes in the S group. In conclusion, female dogs with mammary tumor supplemented with immunostimulant functional food have better clinical condition, they demonstrate normal levels of hematological and biochemical exams, particularly GGT.
\end{abstract}

INDEX TERMS: Immunostimulant supplementation, bitches, mammary tumor, functional foods, cancer, GGT, hematologic parameters, chemotherapy.

RESUMO.- Os alimentos funcionais têm sido empregados como adjuvantes no tratamento do câncer de mama. Neste estudo avaliaram-se as respostas hematológicas e bioquímicas clínicas à ação de um alimento funcional administrado a

\footnotetext{
${ }^{1}$ Recebido em 23 de Setembro de 2015

Aceito em 31 de Maio de 2016.

${ }^{2}$ Hospital Veterinário da Escola de Veterinária e Zootecnia, Universidade Federal de Goiás (UFG), Rodovia Goiânia, Nova Veneza, Km 8, Campus Samambaia, Goiânia, G0 74001-970, Brasil.

${ }^{3}$ Departamento de Medicina Veterinária, Escola de Veterinária e Zootecnia, UFG, Campus Samambaia, Av. Esperança s/n, Campus Universitário, Goiânia, GO 74690-900, Brasil. *Autor para correspondência: joycerl@hotmail.com
}

cadelas com diagnóstico de neoplasia mamária maligna. Após a mastectomia, 16 cadelas foram divididas em dois grupos: suplementadas (S) e não suplementadas (NS) com um composto comercial contendo Saccharomyces cerevisiae, mana-

\footnotetext{
${ }^{4}$ Escola de Veterinária e Zootecnia, UFG, Campus Samambaia, Av. Esperança s/n, Campus Universitário, Goiânia, GO 74690-900, Brasil.

${ }^{5}$ Faculdade de Medicina Veterinária, Instituto Unificado de Ensino Superior Objetivo (IUESO), Av. Nicolau Copérnico, Fazenda Botafogo, Jardim da Luz, Goiânia, GO 74690-9000, Brasil.

${ }^{6}$ Departamento de Medicina Veterinária, Setor de Clínica, Escola de Veterinária e Zootecnia, UFG, Campus Samambaia, Av. Esperança s/n, Campus Universitário, Goiânia, GO 74690-900, Brasil.
} 
noligossacarídeos e nutracêuticos. Ambos grupos receberam tratamento quimioterápico com doxorrubicina e carboplatina, alternadamente, em intervalos de 21 dias, por oito sessões, totalizando 168 dias de tratamento. As avaliações clínicas e laboratoriais foram realizadas nos momentos de aplicação do tratamento. Os resultados dos perfis hematológico (hemograma, leucograma e plaquetograma) e bioquímico sérico (ureia, creatinina, albumina, bilirrubina total e direta, alanina aminotransferase, fosfatase alcalina e gama glutamiltransferase - GGT) foram analisados pelo teste de Kruskall Wallis. No grupo $\mathrm{S}$ comprovou-se elevação do peso corporal e não foram observados transtornos gastrointestinais ou outros sinais de alteração clínica ao longo do tratamento. Diferentemente no grupo NS, ocorreu perda de peso e alterações clínicas, como diarreia e vômito. No quadro hematológico, constatou-se leucopenia por linfopenia no grupo de cadelas NS e preservação do valores dentro dos parâmetros considerados normais para a espécie no grupo $\mathrm{S}$. Dentre todas as variáveis da bioquímica clínica, constatou-se apenas a elevação da atividade sérica da GGT nos animais do grupo NS, sem alterações no grupo S. Conclui-se que cadelas com neoplasia mamária quando suplementadas com com alimento funcional imunoestimulante apresentam melhor condição clínica, hematológica e dos níveis bioquímicos, particularmente da GGT.

TEMOS DE INDEXAÇÃO: Imunoestimulante, cadelas, neoplasia mamária maligna, hematologia, bioquímica, alimento funcional, GGT, câncer, quimioterapia.

\section{INTRODUÇÃo}

As neoplasias mamárias malignas são a forma de câncer mais comum em cadelas, principalmente naquelas não castradas (Seleeckx et al. 2011). É fundamental a detecção precoce de neoplasias da glândula mamária, por meio da avaliação física completa, exames laboratoriais, diagnóstico por imagem e avaliação de histopatologia. Essas informações são fundamentais para o estabelecimento do tratamento adequado, indispensável na prevenção de recidiva ou metástase. Embora a cirurgia continue a ser o tratamento de escolha, o tratamento quimioterápico auxilia na prevenção de recidiva e metástase (Novosad 2003).

A escolha de nutrientes adequados que colaboram com uma melhor resposta do organismo frente ao tratamento quimioterápico deve ser feita considerando o estado nutricional, doenças concomitantes, hipermetabolismo e falhas no sistema imune (Bower 1990). A quimioprevenção com alimentos funcionais surge como um instrumento no controle do câncer de mama, tendo como prováveis mecanismos de ação os efeitos anticarcinogênicos, antioxidantes, anti-inflamatórios, anti-hormonais, antiangiogênicos, dentre outros, embora as evidências científicas sejam controversas (Padilha \& Pinheiro 2004).

Estudos in vivo e in vitro indicaram que organismos probióticos podem reduzir o risco de câncer de cólon e ainda determinar aumento no intervalo de recorrência de câncer de bexiga (Singh et al. 2011). O Saccharomyces cerevisiae é uma levedura de fermentação que tem como constituinte estrutural da parede celular o polímero $\beta$-glucana, um polissacarídeo que vem recebendo especial atenção de pes- quisadores por sua bioatividade, principalmente no que se refere à imunomodulação. Outros efeitos benéficos como a atividade antitumoral, anti-inflamatória, antimutagênica, hipocolesterolêmica e hipoglicemiante têm sido relatados (Magnani \& Castro-Goméz 2008). A $\beta$-glucana é um modificador da resposta biológica e, uma vez reconhecida pelo organismo, desencadeia uma série de eventos na resposta imunológica. A modulação da $\beta$-glucana inclui a ativação de macrófagos e linfócitos, além da indução da expressão de diversas citocinas (Magnani \& Castro-Goméz 2008). Diversos estudos de tumores em modelo animal avaliaram o papel da arginina e detectaram a diminuição da incidência de tumor após a exposição aos agentes carcinogênicos, aumento do período de latência, diminuição do intervalo necessário para regressão do tumor e aumento do tempo de sobrevida do animal (Stechmiller et al. 2004).

Está bem estabelecido que a avaliação dos perfis hematológico e bioquímicos em animais com neoplasias são indispensáveis durante o período de tratamento. Desta forma constituiu-se como objetivo deste estudo comparar os parâmetros clínicos e laboratoriais de cadelas tratadas com quimioterapia antineoplasica adjuvante à mastectomia, recebendo ou não nutracêutico comercial (Promu Dog).

\section{MATERIAL E MÉTODOS}

O estudo foi realizado com 16 cadelas selecionadas a partir de uma população de 50 pacientes atendidas no Setor de Oncologia do Hospital Veterinário da Escola de Veterinária e Zootecnia da Universidade Federal de Goiás (HV/EVZ/UFG). 0 projeto foi aprovado pelo Comitê de Ética em Pesquisa da Universidade Federal de Goiás, sob o número 221/11.

Inicialmente foram empregados os critérios de um único clinico oncologista para inclusão dos animais no experimento, tais como a presença de nódulos mamários múltiplos não ulcerados de diâmetro inferior a $5 \mathrm{~cm}$ em ambas as cadeias mamárias; ausência de doenças infecto contagiosas, endócrinas e metabólicas concomitantes detectáveis em exames laboratoriais de rotina; e ausência de metástases detectáveis nos exames radiográfico de tórax e ultrassonográfico de abdômen.

As cadelas foram submetidas ao procedimento cirúrgico de mastectomia total e remoção de linfonodos regionais, os fragmentos dos tecidos mamários tumorais colhidos foram encaminhados para exame histopatológico e avaliação de margem cirúrgica.

De forma aleatória os animais foram distribuídos em dois grupos experimentais (Quadro 1). 0 grupo suplementado (S) alimentava-se de ração prêmio de marcas variadas adicionada do suplemento Promun Dog ${ }^{\circledR}$ [Grupo Organnact, Curitiba, Paraná. Níveis de garantia - aditivo flavorizante $13 \mathrm{~g} / \mathrm{kg}$, lisina (min) 13,8g/ $\mathrm{kg}$, mananoligossacarídeos $64,7 \mathrm{~g} / \mathrm{kg}$, metionina $49 \mathrm{~g} / \mathrm{kg}$, proteína bruta (min) 200g/kg, Saccharomyces cerevisiae (min) 1x108 $\mathrm{UFC} / \mathrm{g}$, treonina (min) $9,202 \mathrm{mg} / \mathrm{kg}$, triptofano $3,200 \mathrm{mg} / \mathrm{kg}$, vitamina $\mathrm{E}(\mathrm{min}) 1,050 \mathrm{UI} / \mathrm{kg}]$ na dose de dois tabletes para cada 10 $\mathrm{kg}$ de peso vivo, em intervalos de $24 \mathrm{~h}$ e pela via oral. 0 grupo não suplementado (NS) recebeu a dieta constituída somente de ração prêmio de marcas variadas.

A partir da avaliação histopatológica do tumor procedeu-se o estadiamento conforme descrito por Cassali et al. (2011). Foram selecionadas para inclusão no estudo aquelas que apresentaram classificação tumor, linfonodo e metástase (TNM) grau II de acordo com Owen (1980).

Após, foi estabelecido o protocolo de quimioterapia alternando 
Quadro 1. Caracterização dos grupos experimentais

\begin{tabular}{lcc}
\hline Caracterização & Grupo suplementado $(\mathrm{n}=8)$ & Grupo não suplementado $(\mathrm{n}=8)$ \\
\hline Idade (anos) & $8,88 \pm 3,64$ & $9,00 \pm 1,31$ \\
Peso corporal (kg) & $13,71 \pm 11,38$ & $7,33 \pm 2,63$ \\
Raça & Pit bull $(\mathrm{n}=1)$ & Pinscher $(\mathrm{n}=1)$ \\
& Dachshund $(\mathrm{n}=1)$ & Coocker $(\mathrm{n}=1)$ \\
& Poodle $(\mathrm{n}=2)$ & Dachshund $(\mathrm{n}=2)$ \\
Histopatologia & Mestiças $(\mathrm{n}=4)$ & Mestiças $(\mathrm{n}=4)$ \\
& Carcinoma sólido de mama $(\mathrm{n}=1)$ & Carcinoma túbulo papilar $(\mathrm{n}=1)$ \\
& Carcinoma túbulo papilar $(\mathrm{n}=1)$ & Carcinoma em tumor misto* $(\mathrm{n}=1)$ \\
& Carcinoma tubular $(\mathrm{n}=1)$ & Carcinoma sólido de mama $(\mathrm{n}=2)$ \\
& Carcinoma complexo de mama $(\mathrm{n}=2)$ & Carcinoma complexo de mama $(\mathrm{n}=2)$ \\
& Carcinossarcoma de mama $(\mathrm{n}=3)$ & Carcinossarcoma de mama $(\mathrm{n}=2)$
\end{tabular}

*Carcinoma em tumor misto associado a carcinoma túbulo papilar.

os fármacos doxorrubicina e carboplatina entre os momentos. Esta foi realizada em oito ciclos consecutivos de 30 dias, pós mastectomia, com intervalos de 21 dias. As avaliações clínicas e laboratoriais (hemograma e bioquímica clínica) ocorreram em todos os momentos (M0, M21, M42, M63, M84, M105, M126, M147, M168).

0 protocolo quimioterápico estabelecido para as cadelas foi o AP-1, descrito por Lanore \& Delprat (2004). Alternadamente foi aplicado doxorrubicina $1 \mathrm{mg} / \mathrm{kg}$ até $10 \mathrm{~kg}$ de peso vivo e $30 \mathrm{mg} /$ $\mathrm{m}^{2}$ para acima de $10 \mathrm{~kg}$ (Fauldoxo ${ }^{\circledR}$, Libbs Farmacêutica Ltda) e $300 \mathrm{mg} / \mathrm{m}^{2}$ carboplatina, (Fauldocarbo ${ }^{\circledR}$, Libbs Farmaceutica Ltda). Os quimioterápicos foram diluídos em 1000mL de solução salina a $0,9 \%$ e aplicados em perfusão lenta na veia cefálica com auxílio de cateter 22G. Para induzir diurese as pacientes receberam $2 \mathrm{mg} / \mathrm{kg}$ de furosemida por via intravenosa, adicionalmente receberam $2 \mathrm{mg} / \mathrm{kg}$ de difenidramina por via intramuscular, aplicada antes do início da administração de doxorrubicina. Em seguida, administraram-se mais $100 \mathrm{~mL}$ de solução salina a 0,9\%, com intuito de eliminar resquícios do quimioterápico no vaso puncionado para evitar lesão vascular.

O tempo decorrido entre a preparação do paciente e administração do quimioterápico foi de duas horas e previamente a cada sessão de quimioterapia as cadelas foram reavaliadas por meio do exame laboratorial e peso corporal.

A colheita de sangue por venopunção jugular para avaliação laboratorial ocorreu com os animais em jejum alimentar de 12 horas. Para o hemograma foram obtidos $2,0 \mathrm{~mL}$ de sangue em tubo com EDTA. Para a bioquímica sérica foram obtidos $8,0 \mathrm{~mL}$ de sangue em tubo sem anticoagulante, que foi centrifugado após retração do coágulo e, em seguida, o soro foi separado por aspiração, armazenado em microtubos de polipropileno de 1,5mL (Eppen$\left.\operatorname{dorf}^{\circledR}\right)$ e congelados $\left(-20^{\circ} \mathrm{C}\right)$ até o momento da realização dos exames. As análises foram realizadas no Laboratório Multiusuário do Programa de Pós-Graduação em Ciência Animal da EVZ/UFG.

A contagem das células sanguíneas foi determinada pelo método automático utilizando-se o aparelho BC 2800 Vet (Auto Hematology Analyzer, Mindray ${ }^{\circledR}$ Bio-Medical Electronics Co. Ltda, Shenzhen-Guangdong), utilizando-se de cartão próprio de leitura para a espécie canina. Para contagem diferencial de leucócitos foram utilizados esfregaços sanguíneos corados em MMG ou panótico.

Na determinação dos analitos foram utilizados reagentes comerciais padronizados (Labtest ${ }^{\circledR}$ - Labtest Diagnóstica S.A., Lagoa Santa, Minas Gerais), com metodologia cinética e colorimétrica, em temperatura de $37^{\circ} \mathrm{C}$, com leitura realizada em analisador bioquímico automático (Cobas Mira Plus ${ }^{\circledR}$, Roche, Jacarepaguá, Rio de Janeiro).

A atividade sérica da alanina aminotransferase (ALT) foi determinada pelo método cinético de tempo fixo seguindo a metodologia de Reitman e Frankel; a da gama glutamiltransferase (GGT) pelo método cinético (Szasz modificado), utilizando-se como substrato a glutamil-p-nitroanilida e a da fosfatase alcalina (ALP)
Quadro 2. Média e desvio padrão (DP) do peso corporal inicial e final $(\mathrm{kg})$, das cadelas com neoplasia mamária maligna submetidas à quimioterapia* e suplementadas $\mathrm{e}$ não suplementadas com Promun $\operatorname{dog}^{\circledR * *}$

\begin{tabular}{cccccc}
\hline Animal & \multicolumn{2}{c}{ Suplementadas } & & \multicolumn{2}{c}{ Não suplementadas } \\
\cline { 2 - 3 } \cline { 5 - 6 } & Peso inicial & Peso final & & Peso inicial & Peso final \\
\hline 1 & 9,4 & 11,0 & & 8,1 & 7,5 \\
2 & 5,9 & 6,4 & & 8,6 & 7,1 \\
3 & 8,4 & $\mathrm{NA}$ & & 10,3 & 7,3 \\
4 & 31,3 & 33,3 & & 6,3 & 5,0 \\
5 & 8,1 & 8,9 & & 6,2 & 5,0 \\
6 & 3,8 & 4,4 & & 3,3 & 2,6 \\
7 & 30,5 & 37,0 & & 11,4 & 9,0 \\
8 & 7,7 & 9,0 & & 4,3 & 3,7 \\
Média & $13,7^{\mathrm{a}}$ & $15,7^{\mathrm{b}}$ & & $7,3^{\mathrm{a}}$ & $5,9^{\mathrm{b}}$ \\
Desvio-padrão & 11,4 & 12,5 & & 2,6 & 2,0 \\
\hline
\end{tabular}

Letras diferentes informam sobre a diferença pelo Teste de $\mathrm{T}$ pareado $(\mathrm{P} \leq 0,05)$. NA = amostra não analisada, morte por atropelamento. * Doxorrubicina, carboplatina; ** Aditivo flavorizante $13 \mathrm{~g} / \mathrm{kg}$, lisina (min)13,8g/kg, mananoligossacarídeos 64,7g/kg, metionina $49 \mathrm{~g} / \mathrm{kg}$, proteína bruta (min) 200g/kg, Saccharomyces cerevisiae (min) 1x108 $\mathrm{UFC} / \mathrm{g}$, treonina (min) $9.202 \mathrm{mg} / \mathrm{kg}$, triptofano $3.200 \mathrm{mg} / \mathrm{kg}$, vitamina $\mathrm{E}$ (min) $1.050 \mathrm{UI} / \mathrm{kg}$.

pelo método cinético de ponto fixo (Roy modificado). As proteínas totais séricas foram quantificadas pelo método colorimétrico de ponto final, por reação com o biureto; a albumina pelo método colorimétrico por reação com o verde de bromocresol; a uréia pelo método enzimático colorimétrico da urease e a creatinina pelo método colorimétrico com solução de picrato em meio alcalino.

0 delineamento experimental foi em parcelas subdivididas, considerando-se como tratamento principal a suplementação (grupos suplementado e não suplementado) e como tratamento secundário, os momentos de colheita para os exames que antecederam cada ciclo de quimioterapia (M0-M168).

Em princípio realizou-se a estatística descritiva dos dados, obtendo-se as medianas, médias, coeficientes de variação, intervalos de confiança e desvios padrão. Como as variáveis mostraram-se não homogêneas e a distribuição não obedeceu à normalidade, optou-se então pela utilização do teste não paramétrico de Kruskall Wallis e Qui-quadrado. A significância estatística adotada foi menor ou igual a $5 \%$. Para as variáveis de peso inicial e peso final foi aplicado o teste $\mathrm{T}$ pareado, com $\mathrm{p}=0,5 \%$.

\section{RESULTADOS}

No grupo suplementado (S) as cadelas permaneceram sem alterações clínicas ao longo da fase experimental. No grupo não suplementado (NS) as pacientes apresentaram efeitos 
adversos grau I conforme critérios estabelecidos pela Veterinary Cooperative Oncology Group - common terminology criteria for adverse events (VCOG-CTCAE) (2011), sinais como alopecia localizada, náusea, vômitos e aumento na frequência e alteração na consistência fecal.

Como complementação da avaliação, as cadelas foram acompanhadas pelo período de um ano após o término do estudo. No grupo não suplementado, constatou-se que duas desenvolveram piometra e foram submetidas à ovariohisterectomia, um animal veio a óbito por atropelamento dois dias antes do M105, ocorreu uma recidiva da neoplasia confirmada por biopsia e dois casos de suspeita de metástase pulmonar avaliados por exame radiográfico e consequente óbito, nove meses após o término da quimioterapia. No grupo suplementado não se observou alterações clínicas ou recidivas.

0 peso médio corporal das cadelas suplementadas foi crescente $(\mathrm{p}=0.002)$ do inicio $(13,71 \pm 11,38 \mathrm{~kg})$ ao final do estudo $(15,71 \pm 12,48 \mathrm{~kg})$ e apresentou-se estatisticamente significativo pelo teste T pareado. Enquanto que no grupo não suplementado o peso médio decresceu de 7,33 $\pm 2,63$ $\mathrm{kg}$ para $5,90 \pm 2,03 \mathrm{~kg}$, também apresentando significativamente diferente $(\mathrm{p}=0.002)$, conforme indicado no Quadro 2.

Os valores da mediana, média, coeficiente de variação, desvio padrão e intervalo de confiança ao longo do tempo, para os diferentes parâmetros do hemograma estão apresentados no Quadro 3 e 4.

Os resultados indicam que nos dois grupos os animais apresentaram valores dentro da normalidade para o número de hemácias, taxa de hemoglobina e hematócrito. Nos momentos M42 e M105 as medianas das variáveis foram menores para o grupo suplementado $(p \leq 0,05)$.

Em relação à contagem de plaquetas no $M 42(p \leq 0,02) o$ grupo $S$ apresentou maior valor que o grupo NS. Observou-se que ambos os grupos mantiveram a contagem global das plaquetas dentro dos limites da normalidade para a espécie.

A contagem dos leucócitos totais indicou que o grupo NS apresentou valores inferiores ao grupo $\mathrm{S}$ nos momentos

\begin{tabular}{|c|c|c|c|c|c|c|c|c|c|c|}
\hline \multicolumn{2}{|c|}{ Momentos/Variáveis } & \multicolumn{2}{|c|}{ Média $\pm D P$} & \multicolumn{2}{|c|}{ Mediana } & \multirow[t]{2}{*}{ Valor de $\mathrm{P}^{* * *}$} & \multicolumn{2}{|c|}{ IC } & \multicolumn{2}{|c|}{$\mathrm{CV}$} \\
\hline & & S & NS & S & NS & & $S$ & NS & $S$ & NS \\
\hline \multirow[t]{4}{*}{ M0 } & hemácias & $7,10 \pm 0,79$ & $6,81 \pm 0,86$ & 6,95 & 6,94 & 0,64 & 0,55 & 0,60 & 11,15 & 12,63 \\
\hline & hemoglobina & $14,28 \pm 1,04$ & $15,33 \pm 2,20$ & 13,90 & 15,45 & 0,14 & 0,72 & 1,52 & 7,31 & 14,34 \\
\hline & hematócrito & $44,40 \pm 3,13$ & $46,56 \pm 6,27$ & 44,40 & 47,55 & 0,27 & 2,17 & 4,34 & 7,05 & 13,46 \\
\hline & plaquetas & $363,13 \pm 248,19$ & $346,8 \pm 159,89$ & 302,00 & 331,00 & 1,00 & 171,99 & 110,80 & 68,35 & 46,11 \\
\hline \multirow[t]{4}{*}{ M21 } & hemácias & $6,71 \pm 0,61$ & $6,62 \pm 0,64$ & 6,91 & 6,98 & 1,00 & 0,42 & 0,45 & 9,13 & 9,74 \\
\hline & hemoglobina & $13,98 \pm 1,38$ & $15,16 \pm 1,60$ & 13,95 & 15,00 & 0,19 & 0,95 & 1,11 & 9,85 & 10,55 \\
\hline & hematócrito & $43,13 \pm 3,65$ & $46,74 \pm 4,33$ & 43,40 & 47,70 & 0,09 & 2,53 & 3,00 & 8,47 & 9,26 \\
\hline & plaquetas & $528,75 \pm 684,48$ & $396,6 \pm 129,42$ & 428,00 & 382,50 & 0,21 & 474,31 & 89,68 & 129,45 & 32,63 \\
\hline \multirow[t]{4}{*}{ M42 } & hemácias & $6,21 \pm 0,45$ & $6,65 \pm 0,55$ & 6,10 & 6,61 & 0,21 & 0,31 & 0,38 & 7,19 & 8,32 \\
\hline & hemoglobina & $13,63 \pm 1,18$ & $15,23 \pm 1,70$ & $13,35 b$ & $15,65^{\mathrm{a}}$ & 0,05 & 0,81 & 1,18 & 8,63 & 11,15 \\
\hline & hematócrito & $41,51 \pm 2,88$ & $45,68 \pm 4,76$ & $40,95 b$ & $46,70^{\mathrm{a}}$ & 0,05 & 1,99 & 3,30 & 6,93 & 10,42 \\
\hline & plaquetas & $592,00 \pm 772,87$ & $341,8 \pm 83,60$ & $483,00^{\mathrm{a}}$ & $342,50^{\mathrm{b}}$ & 0,02 & 535,56 & 57,93 & 130,55 & 24,46 \\
\hline \multirow[t]{4}{*}{ M63 } & hemácias & $6,05 \pm 0,45$ & $6,56 \pm 0,79$ & 6,19 & 6,39 & 0,17 & 0,31 & 0,55 & 7,48 & 12,07 \\
\hline & hemoglobina & $13,64 \pm 1,27$ & $14,71 \pm 2,17$ & 13,70 & 13,85 & 0,29 & 0,88 & 1,50 & 9,29 & 14,72 \\
\hline & hematócrito & $42,31 \pm 3,13$ & $44,64 \pm 6,00$ & 42,50 & 42,50 & 0,60 & 2,17 & 4,16 & 7,40 & 13,45 \\
\hline & plaquetas & $479,75 \pm 557,91$ & $342,6 \pm 100,75$ & 405,00 & 327,50 & 0,40 & 386,60 & 69,81 & 116,29 & 29,40 \\
\hline \multirow[t]{4}{*}{ M84 } & hemácias & $6,18 \pm 0,63$ & $6,79 \pm 1,02$ & 6,20 & 6,45 & 0,16 & 0,44 & 0,71 & 10,26 & 15,01 \\
\hline & hemoglobina & $13,69 \pm 0,87$ & $15,34 \pm 2,96$ & 13,85 & 14,50 & 0,29 & 0,60 & 2,05 & 6,34 & 19,28 \\
\hline & hematócrito & $42,66 \pm 2,77$ & $46,79 \pm 8,60$ & 43,95 & 43,85 & 0,71 & 1,92 & 5,96 & 6,49 & 18,38 \\
\hline & plaquetas & $450,00 \pm 726,91$ & $289,5 \pm 90,35$ & 337,00 & 282,00 & 0,13 & 503,71 & 62,61 & 161,53 & 31,21 \\
\hline \multirow[t]{4}{*}{ M105 } & hemácias & $5,91 \pm 0,81$ & $6,95 \pm 1,19$ & $5,85^{a}$ & $7,18^{\mathrm{b}}$ & 0,05 & 0,56 & 0,82 & 13,75 & 17,08 \\
\hline & hemoglobina & $13,50 \pm 2,00$ & $15,91 \pm 2,74$ & 13,55 & 16,05 & 0,07 & 1,38 & 1,90 & 14,79 & 18,75 \\
\hline & hematócrito & $40,93 \pm 5,81$ & $48,81 \pm 8,19$ & $40,20 \mathrm{~b}$ & $49,25^{a}$ & 0,05 & 4,03 & 5,68 & 14,20 & 16,78 \\
\hline & plaquetas & $342,38 \pm 424,26$ & $303,8 \pm 97,97$ & 291,50 & 286,50 & 0,96 & 293,99 & 67,89 & 123,92 & 32,25 \\
\hline \multirow[t]{4}{*}{ M126 } & hemácias & $6,43 \pm 1,19$ & $6,36 \pm 0,99$ & 6,14 & 6,11 & 0,67 & 0,83 & 0,69 & 18,53 & 15,63 \\
\hline & hemoglobina & $14,53 \pm 2,91$ & $14,40 \pm 2,70$ & 13,40 & 14,15 & 0,59 & 2,02 & 1,87 & 20,04 & 18,75 \\
\hline & hematócrito & $43,79 \pm 8,84$ & $44,28 \pm 7,82$ & 41,40 & 42,85 & 0,08 & 6,13 & 5,42 & 20,19 & 17,65 \\
\hline & plaquetas & $367,43 \pm 391,03$ & $270,9 \pm 73,76$ & 255,00 & 276,50 & 0,67 & 270,97 & 51,11 & 106,42 & 27,23 \\
\hline \multirow{4}{*}{ M147 } & hemácias & $6,50 \pm 0,82$ & $6,31 \pm 0,73$ & 6,33 & 6,35 & 0,46 & 0,57 & 0,51 & 12,55 & 11,63 \\
\hline & hemoglobina & $14,11 \pm 1,55$ & $13,53 \pm 1,86$ & 14,20 & 13,20 & 0,25 & 1,07 & 1,29 & 10,99 & 13,72 \\
\hline & hematócrito & $44,76 \pm 5,28$ & $40,90 \pm 5,24$ & 44,20 & 39,80 & 0,09 & 3,66 & 3,63 & 11,80 & 12,81 \\
\hline & plaquetas & $347,29 \pm 0,379,72$ & $268,8 \pm 109,49$ & 300,00 & 273,00 & 0,29 & 263,13 & 75,87 & 109,34 & 40,74 \\
\hline \multirow[t]{4}{*}{ M168 } & hemácias & $6,29 \pm 1,00$ & $5,64 \pm 1,11$ & 6,71 & 6,09 & 0,17 & 0,69 & 0,77 & 15,88 & 19,64 \\
\hline & hemoglobina & $14,14 \pm 2,27$ & $13,13 \pm 2,08$ & 15,40 & 13,25 & 0,25 & 1,57 & 1,44 & 16,04 & 15,81 \\
\hline & hematócrito & $44,40 \pm 7,55$ & $40,45 \pm 6,21$ & 49,00 & 39,95 & 0,21 & 5,23 & 4,30 & 17,00 & 15,35 \\
\hline & plaquetas & $314,57 \pm 370,52$ & $293,8 \pm 97,05$ & 307,00 & 284,00 & 0,40 & 256,76 & 67,25 & 117,79 & 33,04 \\
\hline
\end{tabular}

\footnotetext{
* Doxorrubicina e carboplatina; ** Aditivo flavorizante $13 \mathrm{~g} / \mathrm{kg}$, lisina (min)13,8g/kg, mananoligossacarídeos 64,7g/kg, metionina 49g/kg, proteína bruta (min) 200g/kg, Saccharomyces cerevisiae (min) 1x108 UFC $/ \mathrm{g}$, treonina (min) $9.202 \mathrm{mg} / \mathrm{kg}$, triptofano $3.200 \mathrm{mg} / \mathrm{kg}$, vitamina E (min) $1.050 \mathrm{UI} / \mathrm{kg} ;{ }^{* * *}$ Teste de Kruskal-Wallis $(\mathrm{P} \leq 0,05)$.
} 
Quadro 4. Média e desvio padrão (DP), mediana, intervalo de confiança (IC) e coeficiente de variação (CV) referentes aos leucócitos totais (LT $\left.-\mathrm{x}^{3} 0^{3} / \mu \mathrm{L}\right)$, neutrófilos segmentados $\left(\mathrm{Seg}-\mathrm{x} 10^{3} / \mu \mathrm{L}\right)$,

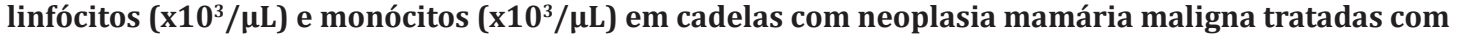
quimioterapia* e suplementadas (S) e não suplementadas (NS) com Promun $\operatorname{dog}^{\circledR * *}$

\begin{tabular}{|c|c|c|c|c|c|c|c|c|c|c|}
\hline \multirow{2}{*}{\multicolumn{2}{|c|}{ Momentos/ Variáveis }} & \multicolumn{2}{|c|}{ Média $\pm D P$} & \multicolumn{2}{|c|}{ Mediana } & \multirow[t]{2}{*}{ Valor deP*** } & \multicolumn{2}{|c|}{ IC } & \multicolumn{2}{|c|}{$\mathrm{CV}$} \\
\hline & & $\mathrm{S}$ & NS & $\mathrm{S}$ & NS & & $\mathrm{S}$ & NS & $\mathrm{S}$ & NS \\
\hline \multirow[t]{4}{*}{ M0 } & LT & $7,90 \pm 1,35$ & $7,57 \pm 2,04$ & 7,95 & 7,00 & 0,07 & 0,93 & 1,41 & 17,13 & 27,02 \\
\hline & Seg & $5,00 \pm 1,62$ & $5,05 \pm 2,87$ & 5,56 & 4,28 & 0,83 & 1,12 & 1,44 & 32,53 & 41,33 \\
\hline & Linfócitos & $2,13 \pm 0,88$ & $1,61 \pm 0,67$ & 1,92 & 1,71 & 0,4 & 0,61 & 0,46 & 41,19 & 41,64 \\
\hline & Monócitos & $0,30 \pm 0,16$ & $0,42 \pm 0,21$ & 0,26 & 0,40 & 0,14 & 0,11 & 0,15 & 0,05 & 0,05 \\
\hline \multirow[t]{4}{*}{ M21 } & LT & $10,52 \pm 4,82$ & $7,80 \pm 2,67$ & 10,10 & 9,10 & 0,32 & 3,34 & 1,85 & 45,83 & 34,33 \\
\hline & Seg & $6,96 \pm 3,68$ & $4,93 \pm 2,18$ & 6,75 & 4,45 & 0,34 & 2,55 & 1,51 & 52,83 & 44,38 \\
\hline & Linfócitos & $1,97 \pm 1,36$ & $1,72 \pm 1,09$ & 1,64 & 1,62 & 0,75 & 0,94 & 0,75 & 69,15 & 63,52 \\
\hline & Monócitos & $0,44 \pm 0,31$ & $0,49 \pm 0,20$ & 0,45 & 0,47 & 0,67 & 0,21 & 0,14 & 0,07 & 0,04 \\
\hline \multirow[t]{4}{*}{ M42 } & LT & $10,13 \pm 4,19$ & $8,46 \pm 3,99$ & 10,95 & 8,20 & 0,46 & 2,90 & 2,77 & 41,33 & 47,26 \\
\hline & Seg & $6,52 \pm 3,84$ & $5,93 \pm 2,82$ & 5,61 & 5,55 & 0,92 & 2,66 & 1,95 & 59,00 & 47,65 \\
\hline & Linfócitos & $2,98 \pm 2,60$ & $1,51 \pm 0,97$ & 2,53 & 1,87 & 0,17 & 1,80 & 0,67 & 87,31 & 64,04 \\
\hline & Monócitos & $0,57 \pm 0,25$ & $0,61 \pm 0,45$ & 0,48 & 0,44 & 0,75 & 0,17 & 0,31 & 0,04 & 0,07 \\
\hline \multirow[t]{4}{*}{ M63 } & LT & $9,30 \pm 2,64$ & $7,37 \pm 2,94$ & 8,70 & 7,20 & 0,21 & 1,83 & 2,03 & 28,43 & 39,9 \\
\hline & Seg & $5,91 \pm 3,03$ & $4,89 \pm 2,00$ & 4,32 & 4,36 & 0,40 & 2,10 & 1,38 & 51,39 & 40,87 \\
\hline & Linfócitos & $2,40 \pm 1,53$ & $1,10 \pm 1,10$ & 1,93 & 0,97 & 0,25 & 1,06 & 0,76 & 63,95 & 71,31 \\
\hline & Monócitos & $0,67 \pm 0,49$ & $0,56 \pm 0,28$ & 0,52 & 0,48 & 1,00 & 0,34 & 0,19 & 0,07 & 0,05 \\
\hline \multirow[t]{4}{*}{ M84 } & LT & $10,02 \pm 2,85$ & $6,21 \pm 2,41$ & $10,20^{\mathrm{a}}$ & $6,00^{\mathrm{b}}$ & 0,02 & 1,97 & 1,67 & 28,45 & 38,83 \\
\hline & Seg & $7,37 \pm 3,80$ & $4,40 \pm 2,21$ & 6,62 & 3,66 & 0,09 & 2,63 & 1,53 & 51,52 & 50,32 \\
\hline & Linfócitos & $2,96 \pm 2,54$ & $1,19 \pm 0,83$ & $2,52^{\mathrm{a}}$ & $1,07^{\mathrm{b}}$ & 0,05 & 1,76 & 0,57 & 85,6 & 70,29 \\
\hline & Monócitos & $0,49 \pm 0,30$ & $0,42 \pm 0,28$ & 0,62 & 0,37 & 0,75 & 0,21 & 0,19 & 0,06 & 0,06 \\
\hline \multirow[t]{4}{*}{ M105 } & LT & $9,68 \pm 4,71$ & $6,57 \pm 3,16$ & 8,60 & 6,65 & 0,29 & 3,26 & 2,19 & 48,64 & 48,13 \\
\hline & Seg & $6,02 \pm 3,40$ & $4,49 \pm 2,36$ & 4,92 & 4,23 & 0,40 & 2,36 & 1,63 & 56,55 & 52,60 \\
\hline & Linfócitos & $2,82 \pm 3,09$ & $1,36 \pm 0,93$ & 2,09 & 1,07 & 0,29 & 2,14 & 0,64 & 109,34 & 68,32 \\
\hline & Monócitos & $0,50 \pm 0,33$ & $0,49 \pm 0,22$ & 0,49 & 0,51 & 0,83 & 0,23 & 0,15 & 0,07 & 0,04 \\
\hline \multirow[t]{4}{*}{ M126 } & LT & $8,73 \pm 41,22$ & $6,81 \pm 3,40$ & 8,8 & 6,35 & 0,14 & 28,56 & 2,36 & 173,43 & 50,01 \\
\hline & Seg & $5,24 \pm 2,88$ & $4,90 \pm 3,56$ & 4,44 & 3,96 & 0,40 & 1,99 & 2,46 & 54,99 & 72,71 \\
\hline & linfócitos & $2,72 \pm 1,77$ & $1,17 \pm 1,01$ & $2,26^{\mathrm{a}}$ & $0,91^{\mathrm{b}}$ & 0,01 & 1,22 & 0,70 & 65,02 & 86,62 \\
\hline & monócitos & $0,42 \pm 0,33$ & $0,44 \pm 0,30$ & 0,35 & 0,37 & 0,83 & 0,23 & 0,21 & 0,08 & 0,07 \\
\hline \multirow[t]{4}{*}{ M147 } & LT & $9,17 \pm 3,41$ & $6,22 \pm 1,33$ & $8,60^{\mathrm{a}}$ & $6,10 \mathrm{~b}$ & 0,05 & 2,36 & 0,92 & 37,2 & 21,5 \\
\hline & Seg & $5,30 \pm 2,47$ & $4,12 \pm 1,08$ & 4,45 & 4,21 & 0,29 & 1,71 & 0,75 & 46,72 & 26,44 \\
\hline & Linfócitos & $2,94 \pm 2,26$ & $1,41 \pm 0,68$ & 2,78 & 1,31 & 0,14 & 1,57 & 0,47 & 77,00 & 48,50 \\
\hline & Monócitos & $0,59 \pm 0,51$ & $0,31 \pm 0,11$ & 0,31 & 0,34 & 0,25 & 0,36 & 0,80 & 0,09 & 0,04 \\
\hline \multirow[t]{4}{*}{ M168 } & LT & $8,14 \pm 3,62$ & $6,53 \pm 1,74$ & 7,5 & 6,60 & 0,29 & 2,51 & 1,20 & 44,52 & 26,68 \\
\hline & Seg & $4,62 \pm 1,62$ & $4,61 \pm 1,79$ & 3,28 & 4,76 & 0,92 & 1,12 & 1,24 & 32,53 & 38,88 \\
\hline & Linfócitos & $2,68 \pm 2,59$ & $1,16 \pm 0,54$ & 2,25 & 1,17 & 0,83 & 1,80 & 0,37 & 96,86 & 46,67 \\
\hline & Monócitos & $0,41 \pm 0,32$ & $0,38 \pm 0,18$ & 0,29 & 0,35 & 0,93 & 0,22 & 0,12 & 0,08 & 0,05 \\
\hline
\end{tabular}

\footnotetext{
* Doxorrubicina e carboplatina; ** Aditivo flavorizante $13 \mathrm{~g} / \mathrm{kg}$, lisina (min)13,8g/kg, mananoligossacarídeos 64,7g/kg, metionina 49g/kg, proteína bruta (min) $200 \mathrm{~g} / \mathrm{kg}$, Saccharomyces cerevisiae (min) 1x108 UFC/g, treonina (min) 9.202mg/kg, triptofano $3.200 \mathrm{mg} / \mathrm{kg}$, vitamina E (min) $1.050 \mathrm{UI} / \mathrm{kg}$; *** Teste de Kruskal-Wallis $(\mathrm{P} \leq 0,05)$.
}

M84 ( $\mathrm{p} \leq 0,02)$ e M147 ( $\mathrm{p} \leq 0,05)$. No grupo suplementado a leucopenia estabeleceu-se somente no M168 [referência de 8 a $13 \times 10^{3} / \mu \mathrm{L}$ - Jain et al. (1993)]. As medianas e a variações obtidas para as contagens absolutas de neutrófilos segmentados não diferiram entre os grupos $(p \geq 0,05)$ e os valores estiveram dentro da normalidade [referência de 3,8 a 9,1x103/ $\mu \mathrm{L}$ - Jain et al. (1993)].

As contagens de linfócitos nas cadelas do grupo $\mathrm{S}$ foram superiores nos momentos M84 ( $\mathrm{p} \leq 0,05)$ e M126 ( $\mathrm{p} \leq 0,01)$. No grupo NS as contagens dos linfócitos estiveram próximas do mínimo para a espécie, ocorrendo linfopenia nos momentos M63 e M126 [referência de 1,1 a 3,9x103/ $\mu \mathrm{L}$ Jain et al. (1993)]. As medianas das contagens absolutas de monócitos (Quadro 4) não diferiram entre os grupos $(\mathrm{p} \geq 0,05)$ e estiveram dentro dos parâmetros normais [referência de 0,2 a $0,7 \times 10^{3} / \mu \mathrm{L}$ - Jain et al. (1993)].

Os valores medianos e as variações obtidas para os parâmetros bioquímicos séricos de ureia, creatinina e albumina estão descritos no Quadro 5.
As concentrações séricas de ureia foram semelhantes $(\mathrm{p} \geq 0,05)$ entre as cadelas dos dois grupos, em todos os momentos experimentais e estiveram dentro dos valores de referência [referência de 21 a 59 mg/dL - Kaneko et al. (1997)]. No M147, o valor mediano da creatinina sérica foi maior no grupo $S$ quando comparado ao grupo NS ( $p \leq 0,03)$. Os valores medianos nos demais momentos experimentais estiveram dentro dos limites fisiológicos para a espécie [referência de 0,5 a 1,5mg/dL - Kaneko et al. (1997)].

Com relação à albumina verificou-se que não houve diferença entre os grupos $(p \geq 0,05)$ e os valores estiveram ligeiramente acima da referência [referência de 2,6 a 3,3g/ dL - Kaneko et al. (1997)].

A atividade sérica da fosfatase alcalina (Quadro 5) foi superior $(\mathrm{p} \leq 0,04)$ no momento M147 no grupo S, entretanto, mais uma vez, os valores estiveram dentro dos limites da normalidade para a espécie estudada [referência de 20 a 150 U/L - Kaneko et al. (1997)]. 
Quadro 5. Média e desvio padrão (DP), mediana, intervalo de confiança (IC) e coeficiente de variação (CV) das concentrações séricas de ureia $(\mathrm{mg} / \mathrm{dL})$, creatinina $(\mathrm{mg} / \mathrm{dL})$, albumina $(\mathrm{g} / \mathrm{dL})$, alanina aminotransferase ALT (U/L) e fosfatase alcalina ALP(U/L) e GGT (U/L) em cadelas com neoplasia mamária maligna tratadas com quimioterapia* e suplementadas (S) e não suplementadas (NS) com Promun dog ${ }^{\circledR * *}$

\begin{tabular}{|c|c|c|c|c|c|c|c|c|c|c|}
\hline \multirow{2}{*}{\multicolumn{2}{|c|}{ Momentos/Variável }} & \multicolumn{2}{|c|}{ Média $\pm D P$} & \multicolumn{2}{|c|}{ Mediana } & \multirow{3}{*}{$\begin{array}{c}\text { Valor de } \mathrm{P}^{* * *} \\
0,71\end{array}$} & \multicolumn{2}{|c|}{ IC } & \multicolumn{2}{|c|}{$\mathrm{CV}$} \\
\hline & & S & NS & S & NS & & S & NS & $S$ & NS \\
\hline \multirow[t]{6}{*}{ M0 } & Ureia & $34,74 \pm 15,67$ & $35,47 \pm 9,68$ & 34,47 & 37,00 & & 10,86 & 6,71 & 45,12 & 27,29 \\
\hline & Creatinina & $0,71 \pm 0,24$ & $0,84 \pm 0,12$ & 0,67 & 0,80 & 0,09 & 0,16 & 0,08 & 33,20 & 13,85 \\
\hline & Albumina & $3,53 \pm 0,33$ & $3,42 \pm 0,60$ & 3,55 & 3,60 & 0,87 & 0,23 & 0,42 & 9,44 & 17,56 \\
\hline & ALT & $27,97 \pm 14,29$ & $36,17 \pm 17,55$ & 25,51 & 33,94 & 0,14 & 9,90 & 12,16 & 51,08 & 48,52 \\
\hline & ALP & $120,94 \pm 63,95$ & $50,26 \pm 25,76$ & 86,07 & 41,77 & 0,53 & 44,31 & 17,85 & 52,88 & 51,26 \\
\hline & GGT & $13,92 \pm 5,86$ & $16,84 \pm 8,36$ & 14,04 & 13,00 & 0,53 & 4,06 & 5,79 & 42,1 & 49,63 \\
\hline \multirow[t]{6}{*}{ M21 } & Ureia & $32,26 \pm 10,93$ & $36,03 \pm 12,44$ & 34,13 & 33,65 & 0,71 & 7,57 & 8,62 & 33,89 & 34,54 \\
\hline & Creatinina & $0,94 \pm 0,25$ & $0,80 \pm 0,28$ & 0,96 & 0,83 & 0,83 & 0,17 & 0,19 & 26,82 & 34,69 \\
\hline & Albumina & $3,42 \pm 0,20$ & $3,66 \pm 0,53$ & 3,40 & 3,55 & 0,22 & 0,14 & 0,37 & 5,9 & 14,44 \\
\hline & ALT & $23,34 \pm 9,67$ & $33,80 \pm 10,89$ & 23,57 & 35,24 & 0,06 & 6,70 & 7,55 & 41,43 & 32,22 \\
\hline & ALP & $83,09 \pm 66,47$ & $111,51 \pm 91,40$ & 65,66 & 86,4 & 0,12 & 46,06 & 63,34 & 80,00 & 81,97 \\
\hline & GGT & $26,03 \pm 18,43$ & $37,71 \pm 5,31$ & $21,20^{\mathrm{a}}$ & $5,47^{\mathrm{b}}$ & 0,01 & 12,77 & 3,68 & 70,82 & 68,87 \\
\hline \multirow[t]{6}{*}{ M42 } & Ureia & $32,61 \pm 10,38$ & $40,35 \pm 21,80$ & 33,00 & 39,84 & 0,40 & 7,20 & 15,11 & 31,84 & 54,03 \\
\hline & Creatinina & $0,78 \pm 0,29$ & $0,86 \pm 0,32$ & 0,82 & 0,90 & 0,71 & 0,20 & 0,22 & 36,79 & 37,50 \\
\hline & Albumina & $3,53 \pm 0,43$ & $3,38 \pm 0,28$ & 3,55 & 3,35 & 0,40 & 0,30 & 0,19 & 12,20 & 8,30 \\
\hline & ALT & $25,47 \pm 6,74$ & $28,13 \pm 12,21$ & 22,31 & 25,27 & 0,92 & 4,67 & 8,46 & 26,46 & 43,39 \\
\hline & ALP & $94,40 \pm 80,98$ & $58,88 \pm 15,66$ & 73,20 & 61,89 & 0,21 & 56,12 & 10,85 & 85,79 & 26,59 \\
\hline & GGT & $14,88 \pm 9,45$ & $7,06 \pm 4,71$ & 16,90 & 5,05 & 0,10 & 6,55 & 3,27 & 63,50 & 66,73 \\
\hline \multirow[t]{6}{*}{ M63 } & Ureia & $25,30 \pm 4,05$ & $31,52 \pm 11,44$ & 26,30 & 29,90 & 0,53 & 2,80 & 7,93 & 15,99 & 36,29 \\
\hline & Creatinina & $0,81 \pm 0,28$ & $0,87 \pm 0,21$ & 0,75 & 0,88 & 0,87 & 0,19 & 0,15 & 34,25 & 24,16 \\
\hline & Albumina & $3,36 \pm 0,31$ & $3,26 \pm 0,37$ & 3,40 & 3,30 & 0,20 & 0,21 & 0,26 & 9,14 & 11,48 \\
\hline & ALT & $28,51 \pm 28,51$ & $41,01 \pm 32,49$ & 29,63 & 29,8 & 1,00 & 9,42 & 22,52 & 47,67 & 79,23 \\
\hline & ALP & $69,64 \pm 22,70$ & $75,11 \pm 29,46$ & 83,54 & 81,29 & 0,87 & 15,73 & 20,42 & 32,6 & 39,23 \\
\hline & GGT & $20,72 \pm 18,64$ & $13,83 \pm 9,18$ & 12,61 & 11,10 & 0,34 & 12,92 & 6,36 & 89,97 & 66,43 \\
\hline \multirow[t]{6}{*}{ M84 } & Ureia & $28,07 \pm 8,46$ & $34,26 \pm 17,34$ & 26,70 & 33,10 & 0,60 & 5,86 & 12,01 & 30,13 & 50,61 \\
\hline & Creatinina & $0,81 \pm 0,28$ & $0,96 \pm 0,53$ & 0,75 & 0,65 & 0,60 & 0,19 & 0,37 & 34,25 & 55,00 \\
\hline & Albumina & $3,44 \pm 0,71$ & $3,40 \pm 0,23$ & 3,40 & 3,35 & 0,53 & 0,49 & 0,16 & 20,73 & 6,89 \\
\hline & ALT & $25,84 \pm 7,24$ & $29,44 \pm 11,43$ & 26,18 & 27,61 & 0,53 & 5,01 & 7,92 & 28,01 & 38,84 \\
\hline & ALP & $62,21 \pm 34,74$ & $55,89 \pm 21,45$ & 51,78 & 52,04 & 0,92 & 24,07 & 14,86 & 55,85 & 38,38 \\
\hline & GGT & $6,65 \pm 3,89$ & $8,12 \pm 2,74$ & 5,84 & 8,08 & 0,29 & 2,69 & 1,90 & 58,47 & 33,70 \\
\hline \multirow[t]{6}{*}{ M105 } & Ureia & $27,92 \pm 8,12$ & $35,39 \pm 12,52$ & 26,70 & 33,40 & 0,29 & 5,62 & 8,68 & 29,07 & 35,39 \\
\hline & Creatinina & $0,74 \pm 0,25$ & $0,70 \pm 0,31$ & 0,87 & 0,60 & 0,53 & 0,17 & 0,21 & 34,04 & 43,69 \\
\hline & Albumina & $3,33 \pm 0,38$ & $3,45 \pm 0,18$ & 3,50 & 3,50 & 0,46 & 0,26 & 0,13 & 11,34 & 5,30 \\
\hline & ALT & $29,44 \pm 11,81$ & $43,82 \pm 25,10$ & 27,45 & 38,60 & 0,14 & 8,18 & 17,39 & 40,11 & 57,27 \\
\hline & ALP & $70,48 \pm 42,04$ & $73,63 \pm 21,61$ & 50,73 & 74,06 & 0,34 & 29,13 & 14,97 & 59,64 & 29,35 \\
\hline & GGT & $11,33 \pm 8,87$ & $14,13 \pm 7,03$ & 8,07 & 15,36 & 0,25 & 6,15 & 4,87 & 78,32 & 49,77 \\
\hline \multirow[t]{6}{*}{ M126 } & Ureia & $30,77 \pm 9,83$ & $43,85 \pm 23,89$ & 26,00 & 36,85 & 0,64 & 6,81 & 16,55 & 31,94 & 54,47 \\
\hline & Creatinina & $0,75 \pm 0,19$ & $0,85 \pm 0,12$ & 0,77 & 0,88 & 0,46 & 0,13 & 0,08 & 24,89 & 14,23 \\
\hline & Albumina & $2,93 \pm 1,17$ & $3,23 \pm 0,39$ & 3,24 & 3,20 & 0,46 & 0,81 & 0,27 & 39,79 & 11,93 \\
\hline & ALT & $30,77 \pm 9,30$ & $26,10 \pm 7,62$ & 21,70 & 27,68 & 0,40 & 6,44 & 5,28 & 43,00 & 29,21 \\
\hline & ALP & $84,02 \pm 108,00$ & $66,99 \pm 34,67$ & 46,70 & 48,74 & 0,83 & 74,84 & 24,02 & 128,54 & 51,75 \\
\hline & GGT & $9,42 \pm 4,41$ & $11,97 \pm 9,29$ & 10,00 & 8,46 & 0,67 & 3,06 & 6,44 & 46,84 & 77,68 \\
\hline \multirow[t]{6}{*}{ M147 } & Ureia & $31,14 \pm 8,24$ & $43,85 \pm 23,89$ & 30,00 & 36,85 & 0,60 & 5,71 & 16,55 & 26,47 & 54,47 \\
\hline & Creatinina & $1,16 \pm 0,31$ & $0,91 \pm 0,21$ & $1,18^{\mathrm{a}}$ & $0,92^{\mathrm{b}}$ & 0,03 & 0,22 & 0,14 & 27,12 & 22,66 \\
\hline & Albumina & $2,73 \pm 1,14$ & $3,43 \pm 0,33$ & 3,40 & 3,45 & 0,49 & 0,79 & 0,23 & 41,64 & 9,49 \\
\hline & ALT & $17,08 \pm 5,53$ & $46,94 \pm 23,20$ & 18,52 & 43,94 & 0,67 & 3,83 & 16,08 & 32,35 & 49,43 \\
\hline & ALP & $175,02 \pm 222,87$ & $64,06 \pm 29,71$ & $80,09^{a}$ & $64,15^{\mathrm{b}}$ & 0,04 & 154,44 & 20,59 & 127,34 & 46,38 \\
\hline & GGT & $12,58 \pm 5,00$ & $13,70 \pm 11,08$ & 12,96 & 12,80 & 0,17 & 3,46 & 7,68 & 39,73 & 80,88 \\
\hline \multirow[t]{6}{*}{ M168 } & Ureia & $30,83 \pm 12,00$ & $37,86 \pm 9,84$ & 33,2 & 34,00 & 0,40 & 8,31 & 6,82 & 38,91 & 26,00 \\
\hline & Creatinina & $0,79 \pm 10,16$ & $0,79 \pm 0,17$ & 0,72 & 0,76 & 0,64 & 0,11 & 0,12 & 20,82 & 22,00 \\
\hline & Albumina & $3,13 \pm 0,36$ & $3,38 \pm 0,41$ & 3,20 & 3,25 & 0,60 & 0,25 & 0,29 & 11,63 & 12,20 \\
\hline & ALT & $29,00 \pm 7,74$ & $49,44 \pm 15,57$ & $29,80^{\mathrm{b}}$ & $44,45^{\mathrm{a}}$ & 0,03 & 5,36 & 10,79 & 26,68 & 31,49 \\
\hline & ALP & $101,05 \pm 113,39$ & $68,28 \pm 21,58$ & 61,95 & 72,70 & 0,42 & 78,58 & 14,95 & 112,21 & 31,60 \\
\hline & GGT & $9,62 \pm 8,71$ & $12,69 \pm 7,25$ & 5,00 & 11,50 & 0,60 & 6,04 & 5,02 & 90,55 & 57,09 \\
\hline
\end{tabular}

\footnotetext{
* Doxorrubicina, carboplatina, ** Aditivo flavorizante $13 \mathrm{~g} / \mathrm{kg}$, lisina (min)13,8g/kg, mananoligossacarídeos $64,7 \mathrm{~g} / \mathrm{kg}$, metionina $49 \mathrm{~g} / \mathrm{kg}$, proteína bruta (min) 200g/kg, Saccharomyces cerevisiae (min) 1 x108 UFC/g, treonina (min) $9.202 \mathrm{mg} / \mathrm{kg}$, triptofano $3.200 \mathrm{mg} / \mathrm{kg}$, vitamina E (min) $1.050 \mathrm{UI} / \mathrm{kg}$; ${ }^{* * *}$ Teste de Kruskal-Wallis $(\mathrm{P} \leq 0,05)$.
} 
A concentração sérica de alanina aminotransferase (Quadro 5) foi menor no grupo $S(p \leq 0,03)$ no M168. No entanto, a atividade enzimática foi considerada normal em todos os momentos do ensaio [referência de 10 a $80 \mathrm{U} / \mathrm{L}$ Kaneko et al. (1997)].

A atividade sérica da gama glutamiltransferase (Quadro 5) foi semelhante entre os grupos, exceto no M21, quando estava mais elevada no grupo $\mathrm{S}(\mathrm{p} \leq 0,01)$, tendo sido evidenciada elevação de moderada a severa em todos os momentos em um ou outro grupo [referência de 1,2 a 6,4 U/L - Kaneko et al. (1997)].

Quanto à bilirrubina direta e total em ambos os grupos, os valores medianos estiveram dentro dos limites da normalidade. Valores médios \pm desvios-padrão, medianas e valores de $\mathrm{p}$ da variável bilirrubina direta em cada momento de avaliação, de acordo com a suplementação: $M 0(S=0,14 \pm 0,05$; $0,12$; $N S=0,13 \pm 0,04 ; 0,15 ; \mathrm{p}=0,67), \mathrm{M} 21 \quad(\mathrm{~S}=0,18 \pm 0,15$; $0,13$; NS $=0,15 \pm 0,08 ; 0,12 ; \mathrm{p}=0,87) ; \mathrm{M} 42$ ( $\mathrm{S}=0,11 \pm 0,09$; $0,10 ; N S=0,10 \pm 0,05 ; 0,08 ; p=0,67), M 63(S=0,12 \pm 0,05 ; 0,10$; $\mathrm{NS}=0,18 \pm 0,11 ; 0,17 ; \mathrm{p}=0,56) ; \mathrm{M} 84 \quad(\mathrm{~S}=0,12 \pm 0,09 ; 0,08$; $\mathrm{NS}=0,13 \pm 0,08 ; 0,10 ; \mathrm{p}=0,34), \mathrm{M} 105(\mathrm{~S}=0,09 \pm 0,06 ; 0,07$; $\mathrm{NS}=0,11 \pm 0,05 ; 0,11 ; \mathrm{p}=0,20), \mathrm{M} 126(\mathrm{~S}=0,10 \pm 0,08 ; 0,06$; $\mathrm{NS}=0,17 \pm 0,17 ; 0,10 ; \mathrm{p}=0,56), \mathrm{M} 147(\mathrm{~S}=0,09 \pm 0,04 ; 0,07$; $\mathrm{NS}=0,16 \pm 0,12 ; 0,12 ; \mathrm{p}=0,10), \mathrm{M} 168(\mathrm{~S}=0,10 \pm 0,09 ; 0,08$; $\mathrm{NS}=0,09 \pm 0,05 ; 0,08 ; \mathrm{p}=0,79$ ). Valores médios \pm desviospadrão, medianas e valores de $\mathrm{p}$ da variável bilirrubina total em cada momento de avaliação, de acordo com a suplementação: $\mathrm{M0}(\mathrm{S}=0,20 \pm 0,06 ; 0,18 ; \mathrm{NS}=0,26 \pm 0,12 ; 0,25 ; \mathrm{p}=0,19)$, M21 ( $S=0,30 \pm 0,23 ; 0,19 ; \mathrm{NS}=0,21 \pm 0,10 ; 0,19 ; \mathrm{p}=0,92), \mathrm{M} 42$ $(\mathrm{S}=0,20 \pm 0,09 ; 0,19 ; \mathrm{NS}=0,16 \pm 0,05 ; 0,17 ; \mathrm{p}=0,25), \mathrm{M} 63$ $(\mathrm{S}=0,22 \pm 0,08 ; 0,20 ; \mathrm{NS}=0,30 \pm 0,14 ; 0,35 ; \mathrm{p}=0,60), \mathrm{M} 84$ ( $S=0,25 \pm 0,17 ; 0,16 ; N S=0,24 \pm 0,19 ; 0,16 ; p=0,63), M 105$ $(\mathrm{S}=0,14 \pm 0,09 ; 0,11 ; \mathrm{NS}=0,20 \pm 0,08 ; 0,18 ; \mathrm{p}=0,10), \mathrm{M} 126$ ( $S=0,17 \pm 0,08 ; 0,16 ; N S=0,26 \pm 0,20 ; 0,23 ; p=0,71), M 147$ $(\mathrm{S}=0,12 \pm 0,03 ; 0,12 ; \mathrm{NS}=0,23 \pm 0,12 ; 0,21 ; \mathrm{p}=0,21), \mathrm{M} 168$ $(\mathrm{S}=0,17 \pm 0,14 ; 0,12 ; \mathrm{NS}=0,25 \pm 0,21 ; 0,20 ; \mathrm{p}=0,37)$ [referência de bilirrubina direta 0,06 a $0,12 \mathrm{mg} / \mathrm{dL}$ e de bilirrubina total 0,1 a 0,3 mg/dL - Kaneko et al. (1997)].

\section{DISCUSSÃO}

A quimioterapia na neoplasia mamária é uma terapia adjuvante, que associada à cirurgia, objetiva o aumento da sobrevida. Os principais protocolos utilizados associam dois ou três fármacos (Cirillo 2008). Neste estudo optou-se pela quimioterapia com dois fármacos, a doxorrubina e a carboplatina (Lanore \& Delprat 2004).

A suplementação com imunoestimulante nas cadelas com neoplasia mamária, submetidas à cirurgia e a quimioterapia, produziu melhor resposta clínica, quando comparada a das cadelas não suplementadas. 0 efeito benéfico pode ser atribuído à redução das ações deletérias da enfermidade e da quimioterapia sob o sistema digestivo, clinicamente traduzido por menos episódios de vômito e diarreia, com consequente ganho de peso corporal. Segundo Klemashevich et al. (2014) alterações na microbiota intestinal estão ligadas a disbioses induzidas pelo câncer, de modo que sua restauração ou fortalecimento, pela adição de probióticos ou prebióticos na dieta, representa uma alternativa para evitar a progressão da neoplasia. 0 polissacarí- deo $\beta$-glucana da parede do Saccaromycescerevisiae é um biomodulador que reduz as respostas pró-inflamatórias associadas à septicemia bacteriana (Tzianabos 2000), além de elevar o número de linfócitos no intestino, podendo ser considerado um importante estimulador de imunidade da mucosa do trato gastrointestinal (Tsukada et al. 2003).

0 ganho de peso no grupo suplementado pode estar relacionado aos efeitos do uso de probióticos e prebióticos. Segundo Reig \& Anesto (2002) os probióticos são microrganismos vivos que podem ser agregados como suplementos adicionados aos alimentos, afetando de forma benéfica o desenvolvimento da microbiota no intestino. São também conhecidos como bioterapêuticos, bioprotetores e bioprofiláticos e são utilizados para prevenir as infecções entéricas e gastrointestinais. De acordo com Saad (2006) a definição internacional atualmente aceita é de que os probióticos são microrganismos vivos, que quando administrados em quantidades recomendadas conferem benefícios à saúde do hospedeiro.

Os prebióticos são oligossacarídeos não digeríveis, fermentáveis cuja função é mudar a atividade e a composição da microbiota intestinal com a perspectiva de promover a saúde do hospedeiro. As fibras dietéticas e os oligossacarídeos não digeríveis são os principais substratos de crescimento dos microrganismos dos intestinos. Os prebióticos estimulam o crescimento dos grupos endógenos de população microbiana, tais como as bifidobactérias os lactobacilos, que são considerados benéficos para a saúde humana (Scheid et al. 2013). Dentre os efeitos atribuídos aos prebióticos estão a modulação de funções fisiológicas chaves, como a absorção de cálcio, o metabolismo lipídico, a modulação da composição da microbiota intestinal, a qual exerce o papel primordial na fisiologia intestinal e a redução do risco de câncer de cólon (Roberfroid 2002).

No grupo das cadelas não suplementadas ocorreu uma recidiva da neoplasia de mama, que necessitou de reintervenção cirúrgica e dois casos de metástase pulmonar, que resultaram na morte das cadelas. Segundo Tzianabos et al. (2000) a $\beta$-glucana extraída do Saccaromyces cerevisiae modula a produção de óxido nítrico e de citocinas como TNF- $\alpha$, IL-1 e IL- 6 nos locais de inflamação, além de aumentar os mediadores anti-inflamatórios, como IL-10 e proteína quimiotática de monócitos-1 (MCP-1). Tian et al. (2013) corroboram o mecanismo de ação desempenhado pela $\beta$-glucana do Saccaromyces cerevisiae, ao descrever sua atividade moduladora das respostas inflamatórias inata e adaptativa, mediante suas propriedades anti-tumorais. Portanto, a capacidade de modular o processo inflamatório pode ser a ligação entre a suplementação com o imunoestimulante e a melhor resposta clínica das cadelas.

Os valores médios de hemácias, hematócrito e hemoglobina das cadelas dos dois grupos, mantiveram-se nos limites fisiológicos indicando que o protocolo de quiomioterapia não induziu hipoplasia medular. Resultado semelhante em cães foi descrito por Santana \& Oliveira (2002) em animais recebendo metotrexato e por Calpa et al. (2010) utilizando à cisplatina.

A contagem das plaquetas permaneceu dentro dos limites da normalidade evidenciando que a quimioterapia 
com doxorrubina e carboplatina não afetou sua produção. Santana \& Oliveira (2002) constataram redução no número de plaquetas em cães submetidos a quimioterapia com metotrexato. Weiss et al. (1999) descreveram a quimioterapia, sem identificação do fármaco, para linfoma e outras neoplasias em cães. A menor toxicidade dos fármacos utilizado neste estudo pode justificar o número adequado de plaquetas. No estadiamento da neoplasia das cadelas deste estudo, foi estabelecido o grau II conforme Misdrop et al. (1999) e, para Stockhaus et al. (1999), as plaquetas apresentam redução no seu número em neoplasias mamárias de grau III e grau IV.

O número de leucócitos esteve dentro dos limites da normalidade nos dois grupos (Quadro 4). Calpa et al. (2010) utilizando a cisplatina para quimioterapia relatou valores médios de leucócitos de $9,4 \times 10^{3} / \mu$ l e não descreveu redução no número de leucócitos ao longo do tratamento, entretanto o período máximo de observação dos cães foi de 84 dias. Santana \& Oliveira (2002) avaliando cães saudáveis, sob quimioterapia com metotrexato, durante 36 dias também não observaram diminuição expressiva e uniforme de leucócitos. A redução dos leucócitos aqui observada pode ser atribuída ao maior período de quimioterapia, bem como ao fato das cadelas serem portadoras de neoplasia mamária, o que é corroborado por Weiss et al. (1999), que relata acentuada redução de leucócitos em cães com neoplasia recebendo quimioterápicos.

A contagem média dos neutrófilos e dos monócitos das cadelas dos dois grupos, ao longo do período acompanhado, permaneceu nos limites da normalidade, semelhante aos resultados obtidos por Santana \& Oliveira (2002). Weiss et al. (1999) relataram neutropenia severa em cães com neoplasias mais graves que a apresentada pelas cadelas deste estudo.

A suplementação com imunoestimulante evitou o decréscimo dos linfócitos uma vez que as cadelas do grupo suplementado apresentaram contagens mais elevadas e dentro dos limites fisiológicos para a espécie, durante todo o período acompanhado. No grupo não suplementado as contagens dos linfócitos estiveram próximas do mínimo para a espécie, ocorrendo linfopenia em alguns momentos. Santana \& Oliveira (2002) ao avaliarem cães sob quimioterapia com metotrexato, observaram a presença de linfopenia, cuja gravidade aumentava com a elevação da dose do fármaco. Quanto ao mecanismo de ação do imunoestimulante sob o número dos linfócitos, pode-se inferir que, assim como ele ocasiona aumento de linfócitos no intestino (Tsukada et al. 2003), também poderia apresentar a mesma ação com relação às células precursoras linfoides.

A função renal das cadelas deste estudo não foi afetada pela quimioterapia com doxorrubina e carboplatina, pois as concentrações séricas de creatinina e uréia mantiveram-se dentro dos parâmetros fisiológicos para a espécie. Esse resultado era esperado uma vez que, apesar da excreção da carboplatina ser renal, é um fármaco seguro que pode ser utilizado inclusive em pacientes nefropatas. A doxorrubicina apresenta efeito nefropático cumulativo para felinos, para caninos o efeito tóxico relevante é sobre o coração (Withrow \& Macwen 2007).
Na avaliação do fígado, considerando os parâmetros relacionados à integridade morfológica dos hepatócitos (ALT), das células dos ductos biliares (ALP), função de síntese (albumina) e de excreção (bilirrubina total e indireta) das cadelas deste estudo verificou-se que não ocorreu hepatotoxicidade. 0 que também era esperado uma vez que os quimioterápicos empregados no estudo não causam toxicidade hepática (Withrow \& Macwen 2007).

Ausência de alterações na bioquímica sérica (creatinina, uréia e ALT) em cadelas com tumor mamário tratadas com doxorrubicina e ciclofosfamida também foram relatadas por Daleck et al. (1998).

A única alteração detectada na bioquímica clínica foi a elevação da atividade sérica da GGT, presente desde antes do início da quimioterapia. Em praticamente todos os momentos do estudo os valores estiveram muito acima da normalidade. Ao término da avaliação o grupo não suplementado ainda apresentava atividade sérica elevada de GGT, enquanto que o grupo suplementado apresentou a média dentro do normal. A GGT é uma enzima chave envolvida no metabolismo da glutationa, cuja expressão está significativamente aumentada em neoplasias humanas malignas (Daleck et al. 1998). Na medicina estudos têm sido desenvolvidos focados na possível relação entre a GGT e o risco de câncer, na progressão tumoral, invasão e resistência aos medicamentos (Daleck et al. 1998, Strasak et al. 2008, Corti et al. 2010, Strasak et al. 2010).

Na medicina veterinária ainda não está caracterizada a relação entre a neoplasia e a elevação da atividade sérica da GGT, entretanto Kumaraguruparan et al. (2006) ao avaliarem a relação entre os diferentes estádios clínicos do tumor mamário canino e a metabolização enzimática de xenobióticos, na fase I (citocromo P450 e b5) e na fase II (glutationa S-transferase [GST], $\gamma$-glutamiltranspeptidase [GGT], DT-diaforase [DTD] e [NADPH-diaforase], descreveram concentrações de GGT em tecido neoplásico mamário maiores que as detectadas em tecido mamário normal. A fase I da biotransformação de xenobióticos compreende um conjunto de reações de oxidação, redução e hidrólise que preparam os toxicantes para as reações da fase II. Essas reações, geralmente, modificam a estrutura química da substância mediante adição de um grupo funcional $(-\mathrm{OH}$, -NH2, -SH, ou - $\mathrm{COOH}$ ), o que resulta em um pequeno aumento de hidrofilicidade. As reações de biotransformação de fase II, também chamadas de reações de conjugação, incluem glicuronidação, sulfonação, acetilação, metilação, conjugação com glutationa e conjugação com aminoácidos. É exatamente na fase II que atua a GGT. Desse modo é possível inferir que a elevação da atividade sérica da GGT teve relação com a neoplasia mamária e não com a aplicação dos quimioterápicos.

\section{CONCLUSÕES}

Cadelas com neoplasia mamária suplementadas com imunoestimulante apresentam melhor condição clínica, traduzida por ganho de peso, com redução de efeitos adversos à quimioterapia.

$\mathrm{Na}$ avaliação da bioquímica clínica a suplementação mantém a atividade sérica da GGT em níveis normais. 


\section{REFERÊNCIAS}

Bower R.H. 1990. Nutrition and immune function. Nutr. Clin. Pract. 5:199205.

Calpa C.O., Daleck C. \& Castro J.T. 2010. Evaluación del hemograma en caninos sanos sometidos la administración de cisplatina. Revta MVZ Córdoba. 15(2):2102-2110.

Cassali G.D., Lavalle G.E., De Nardi A.B., Ferreira E., Bertagnolli A.C., Estrela-Lima A., Alessi A.C., Daleck C.R., Salgado B.S., Fernandes C.G., Sobral R.A., Amorim R.L., Gamba C.O., Damasceno K.A., Auler P.A., Magalhães G.M., Silva J.O., Raposo J.B., Ferreira A.M.R., Oliveira L.O., Malm C., Zuccari D.A.P.C., Tanaka N.M., Ribeiro L.R., Campos L.C., Souza C.M., Leite J.S., Soares L.M.C., Cavalcanti M.F., Fonteles Z.G.C., Schuch I.D., Paniago J., Oliveira T.S., Terra E.M., Castanheira T.L.L., Felix A.O.C., Carvalho G.D., Guim T.N., Guim T.N., Garrido E., Fernandes S.C., Maia F.C.L., Dagli M.L.Z., Rocha N.S., Fukumasu H., Grandi F., Machado J.P., Silva S.M.M.S., Bezerril J.E., Frehse M.S., Paes de Almeida E.C. \& Campos C.B. 2011. Consensus for the diagnosis, prognosis and treatment of canine mammary tumors. Braz. J. Vet. Pathol. 4(2):153-180.

Cirillo J.V. 2008. Tratamento quimioterápico das neoplasias mamárias em cadelas e gatas. J. Health Sci. Inst. 26(3):325-327.

Corti A., Franzini M., Paolicchi A. \& Pompella A. 2010. Gamma-glutamyltransferase of cancer cells at the crossroads of tumor progression, drug resistance and drug targeting. Anticancer Res. 30:1169-1182.

Daleck C.R., Franceschini P.H., Alessi A.C., Santana A.E. \& Martins M.I.M. 1998. Aspectos clínicos e cirúrgicos do tumor mamário canino. Ciência Rural 28(1):95-100.

Jain N.C. 1993. Essentials of veterinary hematology. Lea and Febiger, Philadelphia. $417 \mathrm{p}$.

Kaneko J.J., Harvey J.W. \& Bruss M.L. 1997. Clinical Biochemistry of Domestic Animals. 5th ed. Academic Press, San Diego. 932p.

Klemashevich C., Wu C., Howsmon D., Calaniz R., Lee K. \& Jayaraman A. 2014. Rational identification of diet-derived postbiotics for improving intestinal microbiota function. Curr. Opin. Biotechnol. 26:85-90.

Kumaraguruparan R., Subapriya R., Balachandran C., Manohar B.M., Thangadurai A. \& Nagini S. 2006. Xenobiotic-metabolizing enzymes in canine mammary tumors. Vet. J. 172:364-368.

Lanore D. \& Delprat C. 2004. Quimioterapia anticancerígena. 1ํㅡㄹ. Editora Roca, São Paulo. 191p.

Magnani M. \& Castro-Goméz R.J.H. 2008. $\beta$-glucana de Saccaromyces cerevisiae: constituição, bioatividade, obtenção. Semina, Ciênc. Agrárias 29(3):631-650.

Misdrop W., Else R.W. \& Hellmen E. 1999. Histological classification of mammary tumors of the dog and the cat. AFIP 7(1):1-69.

Novosad C.A. 2003. Principles of treatment for mammary gland tumors. Clin. Tech. Small Anim. Pract. 18(2):107-109.

Owen L.N. 1980. TNM Classification of Tumours in Ddomestic Animals. World Health Organization, Geneva.

Padilha P.C. \& Pinheiro R.L. 2004. O papel dos alimentos funcionais na prevenção e controle do câncer de mama. Revta Bras. Cancerol. 50:251-260.
Reig A.L.C. \& Anesto J.B. 2002. Prebióticos y probióticos, una relación beneficiosa. Revta Cub. Aliment. Nutr. 16(1):63-68.

Roberfroid M. 2002. Functional food concept and its application to prebiotics. Digest Liver Dis. 34(Suppl.2):105-110.

Saad S.M.I. 2006. Probióticos e prebióticos: o estado da arte. Revta Bras. Cienc. Farm. 42(1):1-16.

Santana A.E. \& Oliveira V.F. 2002. Evaluation of hematological profile, liver and kidney function after administration of methotrexate in dogs ( $\mathrm{Ca}$ nis familiaris Linnaeus, 1758). Proc. World Veterinary Coongress, World Veterinary Association, Tunis. Tunísia, p.3.

Scheid M.M.A., Moreno Y.M.F., Maróstica-Junior M.R. \& Pastore G.M. 2013. Effect of prebiotics on the health of the elderly. Food Res. Int. 53:426-32.

Seleeckx N., Rooster H., Kroeze E.J.B.V., Ginneken C.V. \& Brantegem L.V. 2011. Canine mammary tumors, an overview. Reprod. Domest. Anim. 46:1112-1131.

Singh K., Kallali B., Kumar A. \& Thaker V. 2011. Probiotics: a review. APJTM 2011:287-290.

Stechmiller J.K., Childress B. \& Porter T. 2004. Arginine immunonutrition in critically ill patients: a clinical dilemma. Am. J. Crit. Care 13:17-23.

Stockhaus C., Kohn B., Rudolph R., Brunnberg L. \& Giger U. 1999. Correlation of haemostatic abnormalities with tumor stage and characteristics in dogs with mammary carcinoma. J. Small Anim. Pract. 40:326-331.

Strasak A.M., Rapp K., Brant L.J., Hilbe W., Gregoty M., Oberaigner W., Ruttman E., Concin H., Diem G., Pfeiffer K.P. \& Ulmer H. 2008. Association of $\gamma$-glutamyltransferase and risk of cancer incidence in men: a prospective study. Cancer Res. 68(10):3970-3977.

Strasak A.M., Goebel G., Concin H., Pfeiffer R.M., Brant L.J., Nagel G., Oberaigner W., Concin N., Diem G., Ruttmann E., Gruber-Moesenbacher U., Offner F., Pompella A., Pfeiffer K.P. \& Ulmer H. 2010. Prospective study of the association of serum $\gamma$-glutamyltransferase with cervical intraepithelial neoplasia iii and invasive cervical cancer. Cancer Res. 70(9):3586-3593.

Tian J., Ma J., Ma K., Guo H., Baidoo Y.Z., Yan J., Lu L., Xu H. \& Wang S. 2013. $\beta$-Glucan enhances antitumor immune responses by regulating differentiation and function of monocyctic myeloid-derived suppressor cells. Eur, J, Immunol. 43:1220-1230.

Tsukada C., Yokoyama H., Miyaji C., Ishimoto Y., Kawamura H. \& Abo T. 2003. Immunoprotetion of intraepithelial limphocytes in the intestine by oral administrations of $\beta$-glucan. Cell. Immunol. 221:1-5.

Tzianabos A.0. 2000. Polysacharide immunomodulators as therapeutic agents: structural aspects and biologic function. Clin. Microbiol. Rev. 13(4):523-533.

Veterinary Cooperative Oncology Group 2011. Common terminology criteria for adverse events (VCOG-CTCAE), following chemotherapy or biological antineoplastic therapy in dogs and cats. Vet. Comp. Oncol. 1:1-30.

Weiss D.J., Evanson O.A. \& Sykes J. 1999. A retrospective study of canine pancytopenia. Vet. Clin. Pathol. 28(3):83-88.

Withrow S.J. \& Macwen E.G. 2007. Small Animal Cclinical Oncology. 4th ed. W.B. Saunders, St Louis. 